\title{
openheart Role of endothelin in microvascular dysfunction following percutaneous coronary intervention for non-ST elevation acute coronary syndromes: a single-centre randomised controlled trial
}

To cite: Guddeti RR, Prasad A, Matsuzawa Y, et al. Role of endothelin in microvascular dysfunction following percutaneous coronary intervention for non-ST elevation acute coronary syndromes: a single-centre randomised controlled trial. Open Heart 2016;3:e000428.

doi:10.1136/openhrt-2016000428

RRG and AP contributed equally to this work.

Received 14 March 2016 Revised 23 May 2016 Accepted 22 June 2016

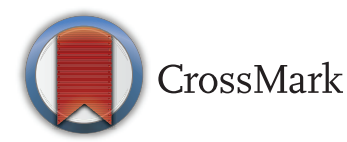

For numbered affiliations see end of article.

Correspondence to Dr Abhiram Prasad; prasad.abhiram@mayo.edu

Raviteja R Guddeti, ${ }^{1,2}$ Abhiram Prasad, ${ }^{1}$ Yasushi Matsuzawa, ${ }^{1}$ Tatsuo Aoki, ${ }^{1}$ Charanjit Rihal, ${ }^{1}$ David Holmes, ${ }^{1}$ Patricia Best, ${ }^{1}$ Ryan J Lennon, ${ }^{3}$ Lilach O Lerman, ${ }^{4}$ Amir Lerman ${ }^{1}$

\section{ABSTRACT}

Objectives: Percutaneous coronary intervention (PCI) for acute coronary syndromes frequently fails to restore myocardial perfusion despite establishing epicardial vessel patency. Endothelin-1 (ET-1) is a potent vasoconstrictor, and its expression is increased in atherosclerosis and after $\mathrm{PCl}$. In this study, we aim to define the role of endothelin in regulating coronary microvascular blood flow and myocardial perfusion following $\mathrm{PCl}$ in patients with non-ST elevation acute coronary syndromes (NSTACS), by assessing whether adjunctive therapy with a selective endothelin $A\left(E T_{A}\right)$ receptor antagonist acutely improves postprocedural coronary microvascular blood flow.

Methods: In a randomised, double-blinded, placebocontrolled trial, 23 NSTACS patients were enrolled to receive an intracoronary infusion of placebo $(n=11)$ or BQ-123 ( $n=12)$ immediately before PCI. Post-PCI coronary microvascular blood flow and myocardial perfusion were assessed by measuring Doppler-derived average peak velocity (APV), and cardiac biomarker levels were quantified.

Results: Compared with the placebo group, APV was significantly higher in the drug group immediately after $\mathrm{PCl}(30(20,37)$ vs $19(9,26) \mathrm{cm} / \mathrm{s} ; \mathrm{p}=0.03)$.

Hyperaemic APV, measured post-adenosine administration, was higher in the BQ-123 group, but the difference did not achieve statistical significance (56 (48, 72 ) vs $46(34,64) \mathrm{cm} / \mathrm{s} ; \mathrm{p}=0.090)$. Maximum coronary flow reserve postprocedure was not different between the two groups $(2.1(1.6,2.3)$ vs $2.5(1.8,3.0))$. Per cent change in creatine kinase isoenzyme MB from the time of $\mathrm{PCl}$ to 8 and 16 hours post-PCI was significantly lower in the drug group compared with the placebo group $(-17$ $(-26,-10)$ vs $26(-15,134) ; p=0.02$ and $-17(-38$, 14) vs 107 (2, 446); $p=0.007$, respectively).

Conclusions: Endothelin is a mediator of microvascular dysfunction during $\mathrm{PCl}$ in NSTACS, and adjunctive selective $\mathrm{ET}_{\mathrm{A}}$ antagonist may augment myocardial perfusion during $\mathrm{PCl}$.

Trial registration number: NCT00586820; Results.

\section{KEY QUESTIONS}

What is already known about this subject?

- Following percutaneous coronary intervention $(\mathrm{PCl})$ for acute coronary syndromes, rise in endothelin-1 (ET-1) levels, a potent vasoconstrictor produced by the vascular endothelium, has been proposed as a potential mediator of reperfusion injury and 'no reflow' phenomenon. Previously, Adlbrecht et al randomly assigned patients to receive intravenous $B Q-123$ at the onset of primary PCI for ST elevation myocardial infarction and demonstrated improved microvascular function using cardiac MRI at 6 days after $\mathrm{PCl}$ and smaller infarct sizes.

What does this study add?

- In this study, we demonstrated the effect of $B Q-123$, a selective endothelin $A\left(E T_{A}\right)$ receptor antagonist, on coronary blood flow velocity in patients undergoing $\mathrm{PCl}$ for non-ST elevation acute coronary syndromes (NSTACS). Also, changes in creatine kinase isoenzyme MB post- $\mathrm{PCl}$ were noted to be significantly lower in the $B Q-123$ group compared to placebo group.

How might this impact on clinical practice?

- Adjunctive use of $\mathrm{ET}_{\mathrm{A}}$ antagonist during $\mathrm{PCl}$ for NSTACS may augment myocardial perfusion and minimise procedure-induced myocardial ischaemia.

\section{INTRODUCTION}

Endothelin-1 (ET-1) is a potent vasoconstrictor produced by the vascular endothelium and in the human heart. ${ }^{12}$ ET-1 mainly acts through two receptors: endothelin receptor type $\mathrm{A}\left(\mathrm{ET}_{\mathrm{A}}\right)$ and type $\mathrm{B} . \mathrm{ET}_{\mathrm{A}}$ has high affinity for ET-1 and is highly expressed 
in vascular smooth muscle cells and in myocardium. ${ }^{1}$ ET-1 contributes to maintenance of basal coronary artery tone in humans with or without coronary artery disease, ${ }^{3}$ and its expression is increased in atherosclerotic coronary arteries. ${ }^{45}$ Prior studies have shown that, in response to mechanical pressure and stretch during angioplasty, there is an acute rise in ET-1 levels. ${ }^{6}{ }^{7}$ Following percutaneous coronary intervention (PCI) for acute myocardial infarction (MI), this rise in ET-1 levels has been proposed as a potential mediator of reperfusion injury and 'no reflow' phenomenon due to its powerful vasoconstrictor properties. ${ }^{8}$

Treatment of high-risk patients with acute coronary syndromes, including unstable angina and non-ST elevation myocardial infarction (NSTEMI) (non-ST elevation acute coronary syndromes (NSTACS)), by PCI is focused mainly on achieving epicardial coronary artery patency. However, in spite of restoring thrombolysis in myocardial infarction (TIMI) grade 3 flow in the epicardial coronary vessels, many patients with NSTACS do not regain normal microvascular perfusion. ${ }^{9}{ }^{10}$ This phenomenon of failure to achieve adequate tissue perfusion, when angiographically detectable, is referred to as 'no reflow', and it is believed to occur as a result of microvascular damage or intramyocardial oedema due to ischaemia. ${ }^{11}$ Failure to restore normal microvascular perfusion is associated with progressive myocardial ischaemia resulting in larger infarcts, lethal ventricular arrhythmias, cardiac failure, cardiogenic shock and death. ${ }^{12}{ }^{13}$ Quantitative assessment of microvascular injury can help predict prognosis after acute MI. ${ }^{14}{ }^{15}$ Understanding the pathophysiology of myocardial malperfusion is important in developing novel therapies. The precise mechanisms responsible for myocardial malperfusion are unknown, but abnormal function of the microcirculation is likely to be a key component.

We hypothesised that the endogenous endothelin system contributes to microvascular dysfunction and impaired myocardial reperfusion following successful PCI for NSTACS and that endothelin receptor antagonism will improve microvascular flow. The aim of the study was to provide new insights into the humoral regulation of the microcirculation in this patient population. Specifically, we assessed the acute effect of adjunctive $\mathrm{BQ}-123$, a selective $\mathrm{ET}_{\mathrm{A}}$ receptor antagonist, on coronary microvascular blood flow immediately following PCI.

\section{METHODS}

\section{Study population}

The study was a prospective, double-blind, randomised, placebo-controlled trial. Twenty-three consecutive patients admitted to the Mayo Clinic for NSTACS between August 2006 and December 2008 were enrolled in the study (figure 1). Inclusion criteria included age $\geq 18$ years, a clinical diagnosis of NSTEMI or unstable angina and requiring clinically indicated PCI. Patients were excluded from the study if they had one or more of the following: systemic hypotension (systolic blood pressure $<90 \mathrm{~mm} \mathrm{Hg}$ ); heart failure or known ejection fraction $<30 \%$; left main disease; culprit lesion is in a saphenous vein graft; $100 \%$ occlusion of the culprit vessel or culprit is an ostial right coronary stenosis; currently enrolled in another active cardiovascular investigational study; severe endocrine, hepatic and renal disorders; pregnancy or lactation; inability to provide consent; Federal Medical Center inmates; and inability or unwillingness to provide informed consent.

\section{Protocol}

After screening for inclusion and exclusion criteria and collecting baseline laboratory blood test data, all of the patients were randomised by a nurse coordinator to either a placebo or the selective $\mathrm{ET}_{\mathrm{A}}$ receptor antagonist BQ-123 (Bachem, Germany). A selective intracoronary infusion of either $300 \mathrm{nmol} / \mathrm{min}$ of $\mathrm{BQ}-123$ or the placebo (saline) was administered for 20 min into the culprit artery, proximal to the lesion, immediately prior to PCI (figure 1). In the event of a very proximal culprit lesion or if selective infusion was precluded, nonselective infusion was attempted. Anti-ischaemic, antiplatelet and anticoagulant therapy before and following randomisation was administered at the discretion of the primary physician and the interventional cardiologist. The following parameters were assessed at baseline and after completion of PCI: heart rate, systolic blood pressure, coronary artery diameter, coronary blood flow $(\mathrm{CBF})$, coronary vascular resistance (CVR) and coronary flow reserve (CFR) in response to intracoronary adenosine in the culprit vessel. CFR was the primary end point. Coronary angiograms were analysed by investigators who were blinded to the assigned treatment.

\section{Coronary angiography and percutaneous coronary intervention}

Coronary angiography and PCI were performed in patients who met the recruitment criteria and after obtaining informed consent. Adjunctive cardiovascular medications were continued as clinically indicated. Routine baseline blood work was conducted pre-PCI. A standard percutaneous right femoral approach was used for all of the patients. Diagnostic coronary angiography was performed using $5 \mathrm{~F}$ Judkins catheter. The sheath was upsized to either 6 or $7 \mathrm{~F}$ for the PCI. A bolus of $70-100 \mathrm{U} / \mathrm{kg}$ intravenous unfractionated heparin was administered, with additional doses given to maintain a therapeutic ACT (250-300 s). After guide engagement, a microcatheter was placed in the culprit artery for the infusion. On completion of the infusion, PCI was performed using techniques, equipment and practices standard to the Mayo Clinic catheterisation laboratory using either a bare metal or drug-eluting stent. ${ }^{16}$ All angiographically significant lesions ( $\geq 70 \%$ stenosis $)$ in the culprit artery were treated. 
Figure 1 Study design. Patient enrolment, randomisation and study protocol. NSTEMI, non-ST elevation myocardial infarction; $\mathrm{PCl}$, percutaneous coronary intervention.

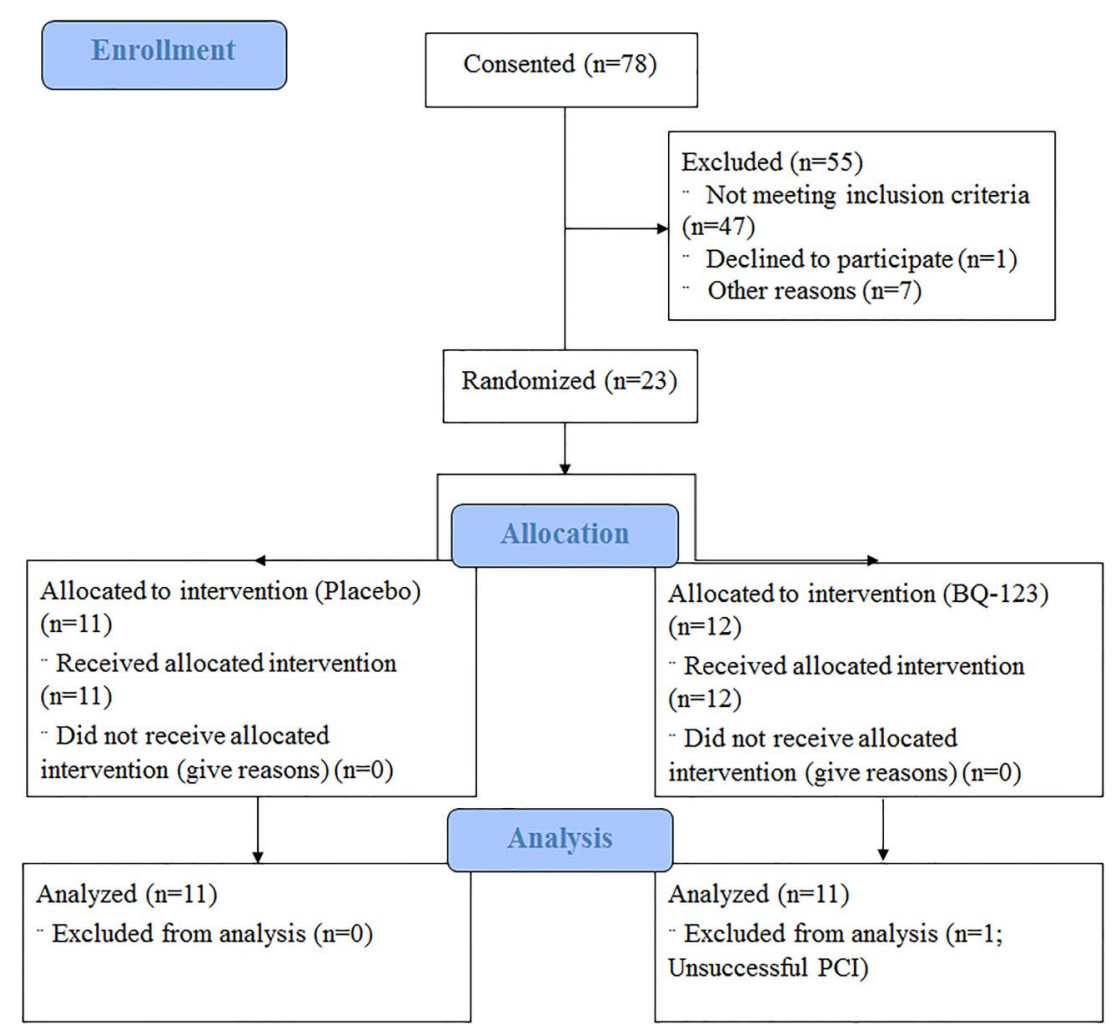

\section{Coronary Doppler study}

Following successful PCI, the coronary guidewire was replaced by a 0.014 inches Doppler guide wire (FloWire, Volcano Incorporated). The wire was positioned in the proximal segment of the target vessel to measure the average peak velocity (APV), systolic and diastolic peak velocities at baseline and during hyperaemia with intracoronary adenosine. Adenosine (Fujisawa, Deerfield, Illinois, USA), an endothelium-independent vasodilator, was administered in incremental bolus doses (30-72 $\mu \mathrm{g}$ in the left main or 18-24 $\mu \mathrm{g}$ in the right coronary artery) to achieve maximal APV. CFR was calculated using the formula: CFR=Hyperaemic APV/baseline APV. ${ }^{17}$ Similarly, CBF and CVR were calculated using the following formulae: ${ }^{18} 19$

$\mathrm{CBF}=\pi(\text { coronary artery diameter } / 2)^{2} \times($ baseline APV/2) $\mathrm{CVR}=$ mean arterial pressure $/ \mathrm{CBF}$

\section{Quantitative coronary angiography}

Quantitative measurements of the coronary arteries were obtained using a computer-based image analysis system (Medis, NC) in the Center for Coronary Physiology and Imaging as mentioned previously. End-diastolic frames, which show segments without foreshortening or overlap from adjacent arteries, were chosen to measure coronary artery diameters $5 \mathrm{~mm}$ from the tip of the Doppler wire in an angiographically smooth proximal segment of the culprit vessel. After appropriate calibration of the guide catheter, image calibration was carried out using a manual edge detection programme to determine the arterial diameters.

\section{Cardiac biomarkers}

Creatine kinase isoenzyme MB (CK-MB) and cardiac troponin $\mathrm{T}(\mathrm{cTnT})$ levels were systematically measured from blood samples collected before intervention, and at 8 and at 16 hours after the procedure, as part of standard clinical practice. Biomarker determinations were performed in the Mayo clinical chemistry laboratory by the mass-determination methods (E Modular CK-MB and cTnT methods, Roche Diagnostics Corporation, Indianapolis, Indiana, USA). Normal reference values for CK-MB are $<6.7 \mathrm{ng} / \mathrm{mL}$ in men and $<3.8 \mathrm{ng} / \mathrm{mL}$ in women $^{20}$ and for cTnT are $<0.01 \mathrm{ng} / \mathrm{mL} .{ }^{21}$

\section{Statistical analysis}

All statistical analyses were performed using JMP V.9 software (SAS Institute, Cary, North Carolina, USA). Continuous variables were expressed as median with $\mathrm{IQR}$ or mean $\pm \mathrm{SD}$ where appropriate. Power calculation was based on a prior similar study in which post-PCI CFR was reported to be $2.35 \pm 0.39 .^{22}$ Pharmacological interventions with a vasodilator following PCI improved CFR by over 0.3. Assuming that the common SD of CFR was no more than 0.60 , we estimated that 25 patients would be required in each group, providing $80 \%$ power to detect a mean difference of 0.49 in CFR between the treatment and control groups. ${ }^{22}$ Categorical variables were expressed in percentages, and the differences 
between the groups were measured by Fisher's exact test or $\chi^{2}$ test. Group differences were analysed by t-test or Wilcoxon signed-rank test for normal and non-normal distributions of variables, respectively. All of the hypotheses tested were two-way, and a $p$ value of $<0.05$ was considered statistically significant. $p$ Values for pretreatment comparisons are provided for descriptive purposes. Since groups were assigned by randomisation, all prerandomised measures must be independent of group assignment.

\section{RESULTS}

\section{Baseline and PCI characteristics}

Both of the study groups were similar with respect to age, gender, body mass index, type of NSTACS, history of prior MI history of prior PCI and conventional cardiovascular risk factors (table 1 ).

Except for one (unable to cross lesion with a wireprobable chronic occlusion), procedural success was achieved in all of the patients $(n=22)$ with postprocedural TIMI 3 flow. Table 2 demonstrates angiographic and procedural characteristics in both of the groups.

\section{Haemodynamic parameters}

No significant changes in blood pressure and heart rate were observed between the two groups following randomisation and following PCI (table 3).

\section{Doppler flow parameters}

In univariate analysis, mean APV immediately after PCI was significantly higher in the BQ-123 group compared with the placebo group ( $\mathrm{p}=0.03$ ) (table 4 and figure 2). Also, APV after intracoronary infusion of adenosine was higher in the BQ-123 group, but of borderline statistical significance $(p=0.09)$. CFR was not significantly different between the groups (table 4). CBF was higher and CVR was lower, immediately after PCI, in the BQ-123-treated group compared with placebo group; however, these differences were not statistically significant (table 4).

\section{Cardiac biomarkers}

In the BQ-123 group, 1 (11\%) out of 9 patients, who had 8-hour post-PCI cardiac biomarker measured, had elevated cTnT and CK-MB levels compared with 7 out of $9(64 \%)$ patients in the placebo group $(\mathrm{p}=0.02$ and $\mathrm{p}=0.02$, respectively). Although the absolute $\mathrm{cTnT}$ levels

Table 1 Baseline clinical characteristics

\begin{tabular}{|c|c|c|c|}
\hline Variable, n (\%) & Placebo $(n=11)$ & Drug $(n=11)$ & p Value* \\
\hline Age, years & $64 \pm 12.5$ & $64.5 \pm 11.2$ & 0.97 \\
\hline Male gender & $9(82)$ & 7 (64), & 0.34 \\
\hline $\mathrm{BMI}, \mathrm{kg} / \mathrm{m}^{2}$ & $31 \pm 6.5$ & $30.4 \pm 5.1$ & 0.95 \\
\hline Diagnosis & $\mathrm{UA}=6$ (55), NSTEMI=5 (45) & UA=3 (27), NSTEMI=8 (73) & 0.19 \\
\hline History of MI & $2(18.2)$ & $1(9.1)$ & 0.53 \\
\hline Prior $\mathrm{PCl}$ & $2(18.2)$ & $3(27.3)$ & 0.61 \\
\hline Family history of CAD & $9(81.8)$ & $5(45.5)$ & 0.19 \\
\hline Current smoking & $3(27.3)$ & $1(9.1)$ & 0.44 \\
\hline Hyperlipidaemia & $10(91)$ & $6(54.6)$ & 0.058 \\
\hline Diabetes mellitus & $2(18.2)$ & $3(27.3)$ & 0.61 \\
\hline Hypertension & $9(81.8)$ & $8(72.7)$ & 0.61 \\
\hline Total cholesterol, mg/dL & $183 \pm 48.5$ & $177.8 \pm 41.2$ & 0.79 \\
\hline TGs, mg/dL & $105(88,164)$ & $104(61,195)$ & 0.65 \\
\hline LDL cholesterol, mg/dL & $111 \pm 46$ & $102 \pm 43$ & 0.63 \\
\hline HDL cholesterol, mg/dL & $45.5 \pm 9.4$ & $44.7 \pm 13$ & 0.87 \\
\hline Creatinine (mg/dL) & $1.0(0.9,1.1)$ & $1.1(0.8,1.2)$ & 0.59 \\
\hline \multicolumn{4}{|l|}{ Baseline medications } \\
\hline Aspirin & $7(64)$ & $5(45)$ & 0.39 \\
\hline Clopidogrel & $1(9)$ & $3(27)$ & 0.27 \\
\hline$\beta$-Blockers & $3(27)$ & $6(55)$ & 0.19 \\
\hline ACE inhibitors & $4(36)$ & $3(27)$ & 0.65 \\
\hline Statins & $4(36)$ & $5(45)$ & 0.67 \\
\hline CCBs & $2(18)$ & $0(0)$ & 0.14 \\
\hline Warfarin & $0(0)$ & $1(9)$ & 0.31 \\
\hline Digoxin & $0(0)$ & $1(9)$ & 0.31 \\
\hline Diuretics & $2(18)$ & $2(18)$ & 1.00 \\
\hline Oral hypoglycaemics & $2(18)$ & $3(27)$ & 0.61 \\
\hline
\end{tabular}


Table 2 Angiographic and procedural characteristics

\begin{tabular}{|c|c|c|c|}
\hline Variable, n (\%) & $\begin{array}{l}\text { Placebo } \\
(n=11)\end{array}$ & $\begin{array}{l}\text { Drug } \\
(n=11)\end{array}$ & p Value* \\
\hline \multirow{6}{*}{$\begin{array}{l}\text { Number of } \\
\text { diseased vessels } \\
\text { (>70\% stenosis) } \\
\text { Culprit vessel }\end{array}$} & $1=4(36)$ & $1=5(45.5)$ & \multirow[t]{3}{*}{0.80} \\
\hline & $2=5(46)$ & $2=5(45.5)$ & \\
\hline & $3=2(18)$ & $3=1(9)$ & \\
\hline & LAD=3 (27) & LAD=6 (55) & \multirow[t]{3}{*}{0.43} \\
\hline & LCx=3 (27) & LCx=2 (18) & \\
\hline & $\mathrm{RCA}=5$ (46) & $\mathrm{RCA}=3(27)$ & \\
\hline \multirow{2}{*}{ Vessels treated } & $1=8(73)$ & $1=10(91)$ & \multirow[t]{2}{*}{0.27} \\
\hline & $2=3(27)$ & $2=1(9)$ & \\
\hline $\begin{array}{l}\text { GP Ilb/Illa } \\
\text { inhibitor use }\end{array}$ & $7(64)$ & $7(64)$ & 1.00 \\
\hline $\begin{array}{l}\text { Clopidogrel } \\
\text { before PCl }\end{array}$ & $1(9)$ & $2(18)$ & 0.53 \\
\hline \multicolumn{3}{|l|}{$\begin{array}{l}\text { Clopidogrel } \\
\text { during PCl } \\
\text { Days from }\end{array}$} & 0.53 \\
\hline \multicolumn{3}{|l|}{$\begin{array}{l}\text { Days from } \\
\text { symptom onset to }\end{array}$} & \multirow[t]{2}{*}{0.61} \\
\hline \multirow{2}{*}{\multicolumn{4}{|c|}{$\begin{array}{l}\mathrm{PCl} \dagger \\
1\end{array}$}} \\
\hline 1 & & & \\
\hline 2 & $2(18)$ & \multicolumn{2}{|l|}{$2(20)$} \\
\hline 3 & $1(9)$ & \multicolumn{2}{|l|}{$2(20)$} \\
\hline 4 & $1(9)$ & \multicolumn{2}{|l|}{$1(10)$} \\
\hline 5 or more & $4(36)$ & $2(20)$ & \\
\hline \multirow{2}{*}{$\begin{array}{l}\text { ACC/AHA lesion } \\
\text { severity grade }\end{array}$} & $A=1(9.1)$ & $A=1(9.1)$ & \multirow[t]{2}{*}{0.54} \\
\hline & $\begin{array}{l}\mathrm{B}=9(81.8), \\
\mathrm{C}=1(9.1)\end{array}$ & $\begin{array}{l}B=7(63.6), \\
C=1(27.3)\end{array}$ & \\
\hline $\begin{array}{l}\text { Culprit lesion } \\
\text { stenosis, \% }\end{array}$ & $88 \pm 8$ & $85 \pm 9$ & 0.56 \\
\hline \multirow[t]{2}{*}{ Stent type } & $\mathrm{BMS}=4(36)$ & $\mathrm{BMS}=0$ & \multirow[t]{2}{*}{0.027} \\
\hline & $\mathrm{DES}=7$ (64) & $\begin{array}{l}\mathrm{DES}=11 \\
(100)\end{array}$ & \\
\hline $\begin{array}{l}\text { Maximum stent } \\
\text { diameter, } \mathrm{mm}\end{array}$ & $3.5(2.5,4)$ & $2.75(2.5,3)$ & 0.051 \\
\hline $\begin{array}{l}\text { Total stent length, } \\
\mathrm{mm}\end{array}$ & $13(13,18)$ & $13(13,18)$ & 0.73 \\
\hline $\begin{array}{l}\text { Max stent } \\
\text { deployment } \\
\text { pressure, } \mathrm{mm} \mathrm{Hg}\end{array}$ & $15 \pm 2.5$ & $14 \pm 2.3$ & 0.19 \\
\hline Baseline LVEF, \% & $57 \pm 7.4$ & $60 \pm 7$ & 0.43 \\
\hline \multicolumn{4}{|c|}{$\begin{array}{l}\text { Data are expressed as number (percentage), median (IQR) and } \\
\text { mean } \pm \text { SD. } \\
\text { `p Values for pretreatment comparisons are provided for } \\
\text { descriptive purposes. } \\
\text { †Days from symptom onset to PCI were unknown for one } \\
\text { participant in the drug group. } \\
\text { ACC/AHA, American College of Cardiology/American Heart } \\
\text { Association; BMS, bare metal stent; DES, drug-eluting stent; GP, } \\
\text { glycoprotein; LAD, left anterior descending artery; LCX, left } \\
\text { circumflex artery; LVEF, left ventricular ejection fraction; PCl, } \\
\text { percutaneous coronary intervention; RCA, right coronary artery. }\end{array}$} \\
\hline
\end{tabular}

in both of the groups were not significantly higher, the median levels maintained a relatively plateau trend in the BQ-123 group compared with those in the placebo group where the levels were observed to rise continuously after procedure (table 5). Compared to pre-PCI levels, CK-MB increased post-PCI in the placebo group $(p=0.05)$, but not in the BQ-123 group $(p=0.21)$. Thus, the per cent changes in CK-MB from pre-PCI to

\begin{tabular}{|c|c|c|c|}
\hline Variable & Placebo $(n=11)$ & Drug $(n=11)$ & p Value \\
\hline \multicolumn{4}{|c|}{ Heart rate, bpm } \\
\hline Predrug & $66 \pm 13$ & $66 \pm 9$ & 0.98 \\
\hline Postdrug & $61 \pm 12$ & $64 \pm 7$ & 0.38 \\
\hline Post-PCl & $70 \pm 19$ & $71 \pm 7$ & 0.82 \\
\hline \multicolumn{4}{|c|}{$\mathrm{SBP}, \mathrm{mm} / \mathrm{Hg}$} \\
\hline Predrug & $126 \pm 22$ & $121 \pm 32$ & 0.67 \\
\hline Postdrug & $123 \pm 22$ & $121 \pm 27$ & 0.83 \\
\hline Post-PCl & $127 \pm 36$ & $116 \pm 25$ & 0.43 \\
\hline \multicolumn{4}{|c|}{$\mathrm{DBP}, \mathrm{mm} / \mathrm{Hg}$} \\
\hline Predrug & $74 \pm 13$ & $68 \pm 13$ & 0.25 \\
\hline Postdrug & $70 \pm 14$ & $66 \pm 10$ & 0.52 \\
\hline Post-PCl & $71 \pm 20$ & $64 \pm 12$ & 0.30 \\
\hline \multicolumn{4}{|c|}{ MAP, $\mathrm{mm} / \mathrm{Hg}$} \\
\hline Predrug & $96 \pm 16$ & $90 \pm 18$ & 0.42 \\
\hline Postdrug & $91 \pm 17$ & $89 \pm 14$ & 0.82 \\
\hline Post-PCl & $95 \pm 26$ & $85 \pm 15$ & 0.29 \\
\hline
\end{tabular}

${ }^{*} p$ Values for pretreatment comparisons are provided for descriptive purposes. Data are expressed as mean \pm SD.

DBP, diastolic blood pressure; MAP, mean arterial pressure; PCI, percutaneous coronary intervention; SBP, systolic blood pressure.

post-PCI at 8 and 16 hours were significantly lower in the BQ-123 group compared with the placebo group, $\mathrm{p}=0.02$ and $\mathrm{p}=0.007$, respectively (table 5 and figure $3 \mathrm{~A}$ ). A similar trend was seen for cTnT levels, but these differences were not statistically significant (figure 3B).

\section{Dosage and safety of $\mathrm{BQ}-123$}

No adverse effects were reported during or after intracoronary infusion of $300 \mathrm{nmol} / \mathrm{min}$ of BQ-123.

\section{DISCUSSION}

The present study among NSTACS patients demonstrates that administration of intracoronary BQ-123, a selective $\mathrm{ET}_{\mathrm{A}}$ antagonist, is associated with higher CBF velocity and diminished cardiac biomarker elevation following PCI. Moreover, it establishes the safety of selective $\mathrm{ET}_{\mathrm{A}}$ receptor antagonism with $\mathrm{BQ}-123$ during percutaneous revascularisation in NSTACS.

To the best of our knowledge, this is the first study to assess the role of endogenous ET-1 during PCI in NSTACS. We observed that BQ-123 infusion was associated with a 50\% higher blood flow velocity, immediately after PCI, compared to those receiving placebo. Doppler-derived measures of blood flow velocity have been shown to correlate with adverse cardiac outcomes following MI. ${ }^{14}{ }^{15}$ In our study, although not statistically significant, the CFR post-PCI, in the absence of an angiographically significant epicardial stenosis, was lower in the BQ-123-treated patients. This may seem counterintuitive, but we believe that it can be accounted for by the higher resting blood flow in the BQ-123-treated group. Potentially, delayed measurements may have yielded different results once autoregulation would have 
Table 4 Coronary haemodynamic variables

\begin{tabular}{|c|c|c|c|}
\hline Variable, n (\%) & Placebo $(n=11)$ & Drug $(n=11)$ & p Value \\
\hline Immediate post-PCI APV, $\mathrm{cm} / \mathrm{s}$ & $19(9,26)$ & $30(20,37)$ & $0.030^{*}$ \\
\hline Immediate post-PCI DSVR & $1.7(1.3,3.5)$ & $2(1.4,3.2)$ & 0.93 \\
\hline CBF immediately after $\mathrm{PCl}, \mathrm{mL} / \mathrm{min}$ & $53(31,94)$ & $80(43,119)$ & 0.19 \\
\hline CVR immediately after $\mathrm{PCl}, \mathrm{mm} \mathrm{Hg} / \mathrm{mL}$ & $2.1(1,2.6)$ & $1.0(0.8,1.7)$ & 0.15 \\
\hline Adenosine APV, $\mathrm{cm} / \mathrm{s}$ & $46(34,64)$ & $56(48,72)$ & 0.090 \\
\hline Adenosine DSVR & $1.9 \pm 0.9$ & $1.6 \pm 0.5$ & 0.24 \\
\hline Post-adenosine CBF, mL/min & $120(84,242)$ & $127(104,313)$ & 0.55 \\
\hline Post-adenosine CVR, mm Hg/mL & $0.65(0.38,1.55)$ & $0.59(0.35,0.8)$ & 0.50 \\
\hline Max CFR & $2.5(1.8,3)$ & $2.1(1.6,2.9)$ & 0.39 \\
\hline
\end{tabular}

reduced the resting blood flow. Our findings suggest that ET-1 is a mediator of PCI-related microvascular injury and impaired blood flow.

Plasma ET-1 levels are known to rise acutely following an MI. ${ }^{23}$ The highest ET-1 expression in atherosclerotic arteries occurs in active plaques and in response to mechanical stretch during PCI. ${ }^{6}{ }^{7}$ ET-1 levels peak at $\sim 1$ hour post-PCI, and we hypothesise that vascular injury is likely to occur in this time window. ${ }^{24-26}$ Adjunctive $\mathrm{ET}_{\mathrm{A}}$ antagonism during PCI likely diminishes vasoconstriction, by inhibiting the direct and indirect (via augmenting angiotensin II, norepinephrine and serotonin) effects of ET-1.

Endothelin antagonists have been approved for the treatment of pulmonary hypertension and have been investigated in heart failure. BQ-123 is a peptide consisting of five amino acids. Several clinical studies in coronary and peripheral circulation with BQ-123 have been published. ${ }^{27}$ Dosing of BQ-123 in the present study was based on the observation that in patients with angiographically normal coronary arteries and in those with mild coronary atherosclerosis, intracoronary infusion of
BQ-123, at doses ranging from 40 to $300 \mathrm{nmol} / \mathrm{min}$, dilates the epicardial and microvessels and improves endothelial dysfunction. ${ }^{3}{ }^{28-30}$ Our work extends the findings of Adlbrecht et al, who randomly assigned patients to receive intravenous BQ-123 at $400 \mathrm{nmol} / \mathrm{min}$ or placebo over $60 \mathrm{~min}$, starting at the onset of primary PCI for ST elevation myocardial infarction (STEMI). Improved microvascular function was detected in the BQ-123 group using cardiac MRI at 6 days after PCI. This was associated with smaller enzymatic infarct sizes. ${ }^{31}$ Also, at 6 months, left ventricular ejection fraction was noted to be significantly higher in the BQ-123 group compared to the placebo group (63\% (58-69) vs $59 \%$ (51-66); $\mathrm{p}=0.047$ ).

Elevations in cardiac biomarkers in NSTACS identify patients with severe and complex coronary lesions and a greater thrombus burden. ${ }^{32}$ However, more recent investigations in NSTACS patients have demonstrated that elevations in cardiac biomarkers are also a marker of impaired myocardial perfusion. ${ }^{33}$ Accordingly, in the present study, the fact that improved parameters of CBF with BQ-123 were associated with a diminished increase
Figure 2 Average peak velocity. APV $(\mathrm{cm} / \mathrm{s})$ in drug and placebo groups immediately post- $\mathrm{PCl}$ and after intracoronary adenosine infusions.

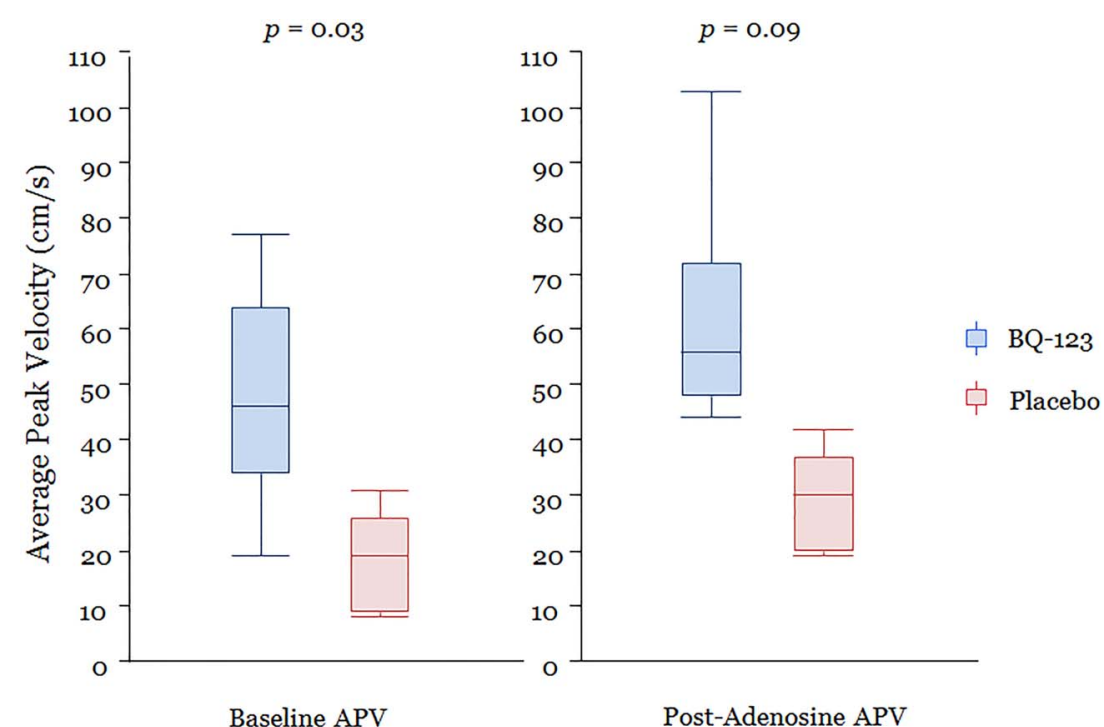

Baseline APV 
Table 5 Cardiac biomarker characteristics

\begin{tabular}{|c|c|c|c|}
\hline Cardiac biomarkers & Placebo $(n=11)$ & Drug $(n=11)$ & p Value \\
\hline \multicolumn{4}{|l|}{ Troponin $T(n g / m L)$} \\
\hline Immediate pre-PCI & $0.03(0.01,0.13)$ & $0.04(0.01,0.28)$ & 0.44 \\
\hline 8 hours & $0.07(0.01,0.15)$ & $0.045(0.03,0.16)$ & 0.67 \\
\hline 16 hours & $0.14(0.01,0.18)$ & $0.06(0.02,0.45)$ & 0.84 \\
\hline$\%$ Change from immediate pre- $\mathrm{PCl}$ to 8 hours & $35(0,300)$ & $25(-6,68)$ & 0.34 \\
\hline$\%$ Change from immediate pre- $\mathrm{PCl}$ to 16 hours & $96(0,220)$ & $33(0,73)$ & 0.18 \\
\hline$\%$ Change from 8 to 16 hours & $0(-7,45)$ & $0(-4,3)$ & 0.47 \\
\hline \multicolumn{4}{|l|}{$C K-M B(n g / m L)$} \\
\hline Immediate pre-PCI & $2.8(2,3.9)$ & $5.5(2.9,10.5)$ & 0.11 \\
\hline 8 hours & $3.8(2.8,9.1)$ & $4.8(2.7,7.7)$ & 0.91 \\
\hline 16 hours & $11(3.03,16.18)$ & $4.4(2.8,8.7)$ & 0.23 \\
\hline$\%$ Change from immediate pre- $\mathrm{PCI}$ to 8 hours & $26(-15,134)$ & $-17(-26,-10)$ & $0.020^{*}$ \\
\hline$\%$ Change from immediate pre- $\mathrm{PCI}$ to 16 hours & $107(2,446)$ & $-17(-38,14)$ & $0.007^{*}$ \\
\hline$\%$ Change from 8 to 16 hours & $27(3,82)$ & $-3(-18,14)$ & 0.11 \\
\hline
\end{tabular}

Figure 3 (A) Percentage change in CK-MB levels. Percentage change in $\mathrm{CK}-\mathrm{MB}$ levels from the time of $\mathrm{PCl}$ to 8 and 16 hours post-PCl. (B) Percentage change in cTnT levels. Percentage change in cTnT from the time of $\mathrm{PCl}$ to 8 and 16 hours after $\mathrm{PCl}$.
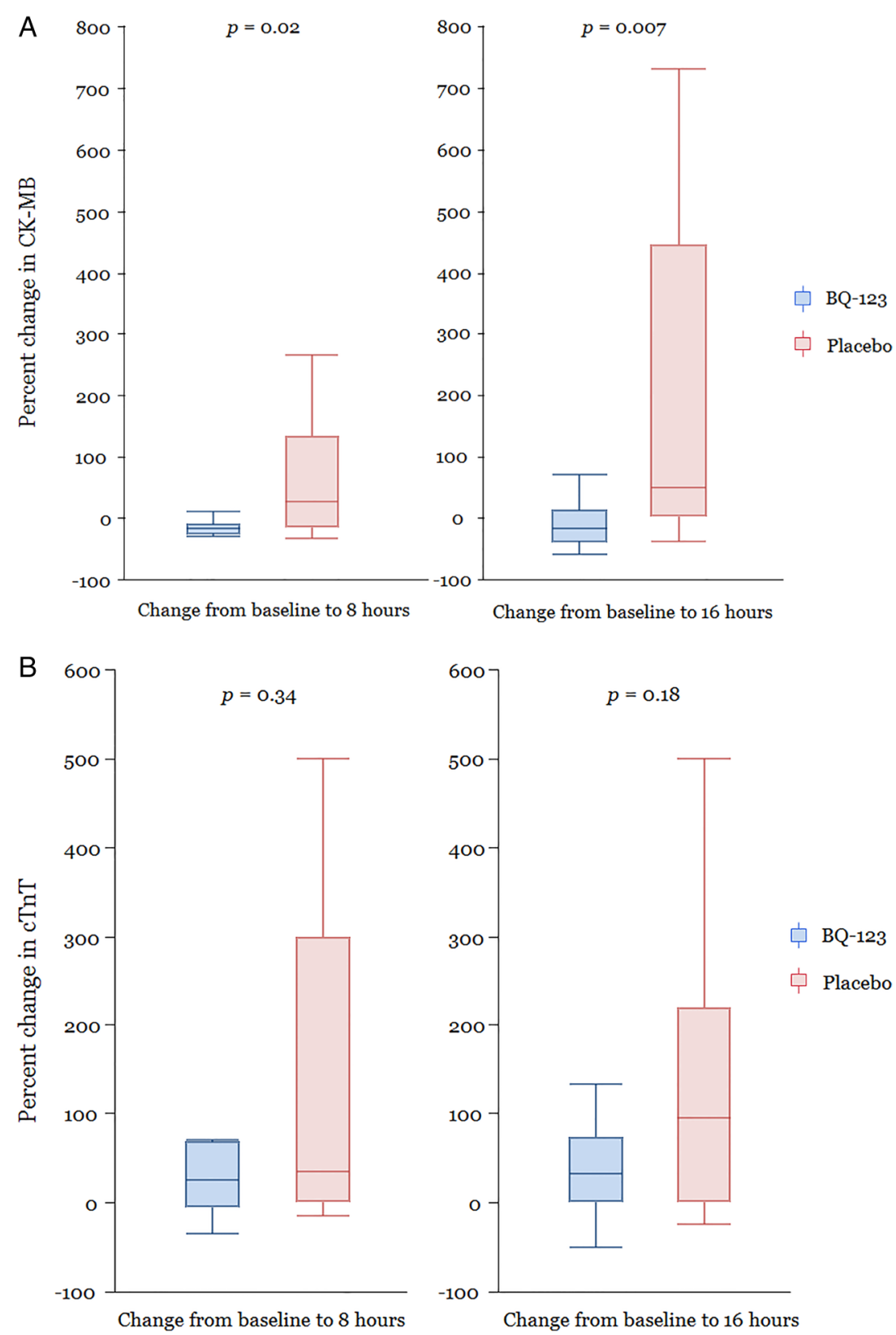
of CK-MB and troponin following PCI suggests that the augmented microvascular perfusion is likely to lead to clinically meaningful benefits. Our findings mirror those of Adlbrecht $e t a l^{\beta 1}$ who reported smaller infarct sizes in STEMI patients treated with BQ-123 during primary PCI.

Studies have previously reported that in patients undergoing PCI, elevated cardiac biomarkers are associated with higher subsequent coronary events and mortality. Furthermore, the risk of adverse outcomes increases with any level of rise in cardiac enzymes. ${ }^{34}$

\section{Limitations}

Our study is subject to several limitations. First, the small size raises the distinct possibility of a statistical type 2 error with differences not being detected in baseline characteristics and/or indices of coronary haemodynamics and flow. The inability to reach the target recruitment was to large extent due to the insufficient supply of the study drug BQ-123 during the study period. This factor limits the strength of our conclusions regarding the role of endothelin in microvascular dysfunction post-PCI. Further large-scale, randomised clinical trials are required to define the role of endothelin in microvascular dysfunction post-PCI in patients with NSTACS and determine the efficacy of intraprocedural administration of selective $\mathrm{ET}_{\mathrm{A}}$ antagonists in preventing impaired myocardial perfusion. Second, lack of pre-PCI coronary flow parameters limits the precise assessment of the effect of BQ-123 on post-PCI measurements. However, this was not feasible using Doppler techniques since the presence of an epicardial stenosis precludes assessment of microvascular blood flow. Newer techniques such as the index of microvascular resistance that can be used even in the presence of epicardial stenosis should be incorporated in future studies. Third, the use of the Doppler wire and cardiac biomarkers only to assess the microcirculation and myocardial injury, respectively, has inherent limitations. Our findings would be strengthened had we concomitantly used additional techniques to assess myocardial perfusion and infarct size. However, our study design was based on the most applicable and readily available techniques. While baseline haemodynamic, angiographic and procedural variables were comparable in the two groups, stent diameter was smaller in the BQ-123 group, and this was of borderline statistical significance. This may have potentially impacted our results. Finally, our study did not meet the primary end point, and hence our conclusions are derived from secondary end points with inherent potential for bias from a study of small sample size.

\section{Conclusions}

The current study demonstrates that adjuvant administration of $\mathrm{ET}_{\mathrm{A}}$ receptor antagonist during PCI is safe and results in improved microvascular flow patterns in association with improved tissue-level myocardial perfusion. The study further supports the role of ET pathway in the regulation of myocardial blood flow following PCI. Further large-scale, randomised studies are required to define the role of endothelin as the common denominator of elevated cardiac biomarker levels and abnormal coronary Doppler flow parameters and also develop a new therapeutic strategy to prevent PCI-related myocardial injury.

Author affiliations

${ }^{1}$ Division of Cardiovascular Diseases, Mayo College of Medicine, Rochester, Minnesota, USA

${ }^{2}$ Division of Internal Medicine, Marshfield Clinic, Marshfield, Wisconsin, USA ${ }^{3}$ Division of Biomedical Statistics and Informatics, Mayo College of Medicine, Rochester, Minnesota, USA

${ }^{4}$ Division of Nephrology and Hypertension, Mayo Clinic, Rochester, Minnesota, USA

Acknowledgements The authors sincerely thank Ms Rebecca E. Nelson for study coordination and Ms Jonella M. Tilford and Ms Lynn E. Polk for imaging technical support.

Contributors RRG, AP, YM, TA, RJL and AL are responsible for conception and design or analysis and interpretation of data. RRG, AP, YM, TA, CR, DH, $\mathrm{PB}, \mathrm{RJL}, \mathrm{LOL}$ and $\mathrm{AL}$ drafted the manuscript or revised it critically for important intellectual content. Manuscript submitted was approved finally by RRG, AP and AL.

Funding This study was funded by Department of Cardiology, Mayo Clinic and Mayo Foundation.

Competing interests None declared.

Patient consent Consent was obtained from patients.

Ethics approval This study was approved by IRB, Mayo Clinic, Rochester, Minnesota, USA

Provenance and peer review Not commissioned; internally peer reviewed.

Data sharing statement No additional data are available.

Open Access This is an Open Access article distributed in accordance with the Creative Commons Attribution Non Commercial (CC BY-NC 4.0) license, which permits others to distribute, remix, adapt, build upon this work noncommercially, and license their derivative works on different terms, provided the original work is properly cited and the use is non-commercial. See: http:// creativecommons.org/licenses/by-nc/4.0/

\section{REFERENCES}

1. Haynes WG, Webb DJ. The endothelin family of peptides: local hormones with diverse roles in health and disease? Clin Sci 1993;84:485-500.

2. Mathew V, Hasdai D, Lerman A. The role of endothelin in coronary atherosclerosis. Mayo Clin Proc 1996;71:769-77.

3. Kyriakides ZS, Kremastinos DT, Bofilis E, et al. Endogenous endothelin maintains coronary artery tone by endothelin type A receptor stimulation in patients undergoing coronary arteriography. Heart 2000;84:176-82.

4. Lerman A, Edwards BS, Hallett JW, et al. Circulating and tissue endothelin immunoreactivity in advanced atherosclerosis. $N$ Engl $J$ Med 1991;325:997-1001.

5. Lerman A, Holmes DR Jr, Bell MR, et al. Endothelin in coronary endothelial dysfunction and early atherosclerosis in humans. Circulation 1995:92:2426-31.

6. Hasdai D, Holmes DR Jr, Garratt KN, et al. Mechanical pressure and stretch release endothelin-1 from human atherosclerotic coronary arteries in vivo. Circulation 1997;95:357-62.

7. Petronio AS, Amoroso G, Limbruno U, et al. Endothelin-1 release from atherosclerotic plaque after percutaneous transluminal coronary angioplasty in stable angina pectoris and single-vessel coronary artery disease. Am J Cardiol 1999;84:1085-8, A9.

8. Galiuto L, DeMaria AN, del Balzo U, et al. Ischemia-reperfusion injury at the microvascular level: treatment by endothelin A-selective 
antagonist and evaluation by myocardial contrast echocardiography. Circulation 2000;102:3111-16.

9. Prasad A, Stone GW, Holmes DR, et al. Reperfusion injury, microvascular dysfunction, and cardioprotection: the "dark side" of reperfusion. Circulation 2009;120:2105-12.

10. Bolognese L, Ducci K, Angioli P, et al. Elevations in troponin I after percutaneous coronary interventions are associated with abnormal tissue-level perfusion in high-risk patients with non-STsegment-elevation acute coronary syndromes. Circulation 2004;110:1592-7.

11. Piana RN, Paik GY, Moscucci M, et al. Incidence and treatment of 'no-reflow' after percutaneous coronary intervention. Circulation 1994:89:2514-18.

12. Yamamuro A, Akasaka $\mathrm{T}$, Tamita $\mathrm{K}$, et al. Coronary flow velocity pattern immediately after percutaneous coronary intervention as a predictor of complications and in-hospital survival after acute myocardial infarction. Circulation 2002;106:3051-6.

13. Furber AP, Prunier F, Nguyen HC, et al. Coronary blood flow assessment after successful angioplasty for acute myocardial infarction predicts the risk of long-term cardiac events. Circulation 2004; 110:3527-33.

14. Kawamoto T, Yoshida K, Akasaka T, et al. Can coronary blood flow velocity pattern after primary percutaneous transluminal coronary angioplasty [correction of angiography] predict recovery of regional left ventricular function in patients with acute myocardial infarction? Circulation 1999;100:339-45.

15. Akasaka T, Yoshida K, Kawamoto $\mathrm{T}$, et al. Relation of phasic coronary flow velocity characteristics with TIMI perfusion grade and myocardial recovery after primary percutaneous transluminal coronary angioplasty and rescue stenting. Circulation 2000;101:2361-7.

16. Singh M, Rihal CS, Gersh BJ, et al. Mortality differences between men and women after percutaneous coronary interventions. A 25-year, single-center experience. J Am Coll Cardiol 2008;51:2313-20.

17. Klocke FJ. Measurements of coronary flow reserve: defining pathophysiology versus making decisions about patient care. Circulation 1987;76:1183-9.

18. Doucette JW, Corl PD, Payne HM, et al. Validation of a Doppler guide wire for intravascular measurement of coronary artery flow velocity. Circulation 1992;85:1899-911.

19. Quyyumi AA, Dakak N, Andrews NP, et al. Contribution of nitric oxide to metabolic coronary vasodilation in the human heart. Circulation 1995;92:320-6.

20. Mair J, Artner-Dworzak E, Dienstl A, et al. Early detection of acute myocardial infarction by measurement of mass concentration of creatine kinase-MB. Am J Cardiol 1991;68:1545-50.

21. Jaffe AS. 2001-A biomarker odyssey. Clin Chim Acta 1999;284:197-211.
22. Gregorini L, Marco J, Farah B, et al. Effects of selective alpha1- and alpha2-adrenergic blockade on coronary flow reserve after coronary stenting. Circulation 2002;106:2901-7.

23. Omland T, Lie RT, Aakvaag A, et al. Plasma endothelin determination as a prognostic indicator of 1-year mortality after acute myocardial infarction. Circulation 1994;89:1573-9.

24. Malatino LS, Grassi R, Stancanelli B, et al. Release of immunoreactive endothelin from the heart during percutaneous transluminal coronary angioplasty. Am Heart J 1993;126(Pt 1):700-2.

25. Ameli S, Kaul S, Castro L, et al. Effect of percutaneous transluminal coronary angioplasty on circulating endothelin levels. Am J Cardiol 1993;72:1352-6.

26. Cuculi F, Lim CC, van Gaal W, et al. Systemic levels of endothelin correlate with systemic inflammation and not with myocardial injury or left ventricular ejection fraction in patients undergoing percutaneous coronary intervention and on-pump coronary artery bypass grafting. Interact Cardiovasc Thorac Surg 2011;13:585-9.

27. Spratt JC, Goddard J, Patel N, et al. Systemic ETA receptor antagonism with BQ-123 blocks ET-1 induced forearm vasoconstriction and decreases peripheral vascular resistance in healthy men. Br J Pharmacol 2001:134:648-54.

28. Halcox JP, Nour KR, Zalos G, et al. Coronary vasodilation and improvement in endothelial dysfunction with endothelin ET(A) receptor blockade. Circ Res 2001;89:969-76.

29. Kinlay S, Behrendt D, Wainstein M, et al. Role of endothelin-1 in the active constriction of human atherosclerotic coronary arteries. Circulation 2001:104:1114-18.

30. MacCarthy PA, Pegge NC, Prendergast BD, et al. The physiological role of endogenous endothelin in the regulation of human coronary vasomotor tone. J Am Coll Cardiol 2001;37:137-43.

31. Adlbrecht C, Andreas M, Redwan B, et al. Systemic endothelin receptor blockade in ST-segment elevation acute coronary syndrome protects the microvasculature: a randomised pilot study. Eurolntervention 2012;7:1386-95.

32. Heeschen C, van Den Brand MJ, Hamm CW, et al. Angiographic findings in patients with refractory unstable angina according to troponin T status. Circulation 1999;100:1509-14.

33. Wong GC, Morrow DA, Murphy S, et al. Elevations in troponin T and I are associated with abnormal tissue level perfusion: a TACTICS-TIMI 18 substudy. Treat Angina with Aggrastat and Determine Cost of Therapy with an Invasive or Conservative Strategy-Thrombolysis in Myocardial Infarction. Circulation 2002;106:202-7.

34. Califf RM, Abdelmeguid AE, Kuntz RE, et al. Myonecrosis after revascularization procedures. J Am Coll Cardiol 1998;31:241-51. 